\title{
A forma das sentenças téticas anunciativas no português do Brasil
}

\author{
Paulo Pinheiro-Correa*
}

\begin{abstract}
Resumo
Considerando dois tipos diferentes de asserção, que se traduzem sintaticamente por sentenças téticas, por um lado e categóricas, por outro, este estudo analisa a sintaxe de um tipo específico de sentenças téticas, no português brasileiro (PB): as anunciativas, tal como classificadas por Sasse (2006). Dentro destas, analisamos especificamente as manchetes de jornal. Tomando como referencial teórico a Linguística Contrastiva e a Pragmática, tal como discutida em Lambrecht (1994) e em Sasse (1987, 2006), comparamos, em um corpus de manchetes correspondentes provenientes de jornais brasileiros e argentinos, a sintaxe dessas manchetes em espanhol argentino e em português brasileiro. Partindo de dados de uma língua conhecida por marcar uma diferença sintática entre sentenças categóricas e téticas (o espanhol, segundo Sornicola 1995, Lambrecht 2000 e Sasse 2006), buscamos analisar o comportamento sintático dos dados correspondentes em PB. Os resultados demonstraram que, ao contrário do espanhol, todas as manchetes téticas do PB apresentaram a ordem VS e não houve diferença na ordem de constituintes entre as manchetes téticas e categóricas.
\end{abstract}

Palavras-chave: Teticidade. Estrutura Informativa. Português brasileiro. Sentença tética. Sintaxe.

\section{The Form of Annuntiative Thetic Sentences in Brazilian Portuguese}

\begin{abstract}
In this paper we address the syntax of thetic sentences of the annuntiative type (Sasse 2006) in Brazilian Portuguese. We centered our study in newspaper headlines. Within the theoretical framework of Contrastive Linguistics and Pragmatics, discussed by Lambrecht (1994) and Sasse (1987, 1996, 2006), we compared headlines from two Brazilian newspapers and the corresponding ones from two Argentinean newspapers for identifying thetic headlines. Spanish was considered for a contrastive analysis because it is considered a language marking theticity syntactically in word order (Sornicola 1995; Lambrecht 2000; Sasse 2006). This methodological step helped to identify Brazilian thetic data. Results showed that in 24 Brazilian Portuguese data, differently from Spanish, all 19 thetic headlines were VS and there was no word order difference between thetic and categorical headlines.
\end{abstract}

Keywords: Theticity. Information Structure. Brazilian Portuguese. Thetic sentence. Syntax.

Recebido:16/01/2018

Aceito:24/04/2018

* Universidade Federal Fluminense (UFF). Doutor em Linguística. Professor do Departamento de Letras Estrangeiras Modernasda UFF. 
Em uma tradição que remonta ao século XIX, recuperada por Kuroda (1972) e Sasse (1987), entre outros autores, há dois tipos de conteúdo que determinam duas classes básicas de orações, pragmaticamente classificadas: categóricas e téticas ${ }^{2}$. As orações categóricas têm estrutura informativa bipartida: expressam um actante e uma predicação acerca desse actante. As téticas, por sua vez, expressam um estado de coisas ou, alternativamente, a existência de um actante. A diferença entre as orações téticas e categóricas tem sido motivo de amplo debate na literatura, havendo discordância entre os estudiosos sobre se existe de fato uma diferença entre essas orações, como classes gramaticais naturais (ideia defendida por Kuroda 1972 e Sasse 1987, entre outros) ou se a existência das orações téticas é um epifenômeno derivado da estrutura informativa (como defende Kuno 1972, entre outros). As orações téticas também são chamadas de construções de foco sentencial (Lambrecht 2000, Smit 2010).

Exemplificamos estas orações abaixo com dados em português brasileiro (doravante, PB):

Tética:

(1) O meu carro parou de funcionar (exemplo adaptado de Lambrecht 1994, p.14)

Categórica:

(2) O João trouxe o refrigerante e a Sílvia trouxe o bolo.

Através do mero exame da estrutura sintática, os dois exemplos do $\mathrm{PB}$ não revelam a sua estrutura informativa, que é dependente do cotexto e da situação de enunciação. O exemplo (1) é de oração tética porque aqui se trata de uma resposta a uma pergunta sem contexto prévio, como, no exemplo de Lambrecht (1994) em que, no contexto dos EUA, uma pessoa pega um ônibus sobrecarregada de objetos, fazendo a viagem se atrasar e então ela se justifica para os demais passageiros explicando que seu carro quebrou (e por isso teve que tomar o ônibus e pela mesma razão vinha sobrecarregada). Trata-se de um enunciado tético ${ }^{3}$, emitido em um contexto em que nenhum dos elementos mencionados é previsível a partir do contexto nem do cotexto e veicula um estado de coisas sem predicar exclusivamente sobre o carro. Por outro lado, se (1) for uma resposta a uma pergunta do tipo "o que aconteceu com o seu carro", a sentença enunciada vem a ser categórica, pois consta de duas partes, o tema (informação dada, o 'carro', mencionada por quem perguntou e o rema, aporte de informação nova que se faz sobre o tema. Neste caso, informação de que ele parou de funcionar).

Em (2), o que se tem é uma estrutura categórica, em resposta a uma pergunta do tipo: 'quem trouxe tudo isso', enunciada, por exemplo, em uma festa improvisada. A resposta envolve referentes presentes ou no cotexto ou no conhecimento compartilhado dos enunciadores e por isso, apresenta a estrutura tópico (o João, a Silvia) / comentário, também bipartida. O fato de ser bimembre a diferencia das téticas e faz com que seja classificada como categórica.

Sasse (1987), ao analisar a diferença entre orações categóricas e téticas, procura investigar a natureza do conceito de teticidade. As sentenças téticas se opõem às chamadas categóricas pelo fato de as primeiras veicularem apenas informação nova para o contexto, razão pela qual são considerados enunciados cujo conteúdo inteiro está sob a ação de foco (cf., entre outros, Lambrecht 2000). As categóricas, por sua vez, apresentam uma divisão informativa entre tema e rema ou entre tópico e comentário e estabelecem, crucialmente, uma predicação sobre um referente dado, o que as téticas não fazem.

Este trabalho visa a investigar a forma das sentenças téticas do tipo apresentativo no português brasileiro (PB), especificamente, nas manchetes de jornal, através de um estudo comparativo com as manchetes correspondentes em espanhol argentino (doravante, EA). O espanhol marca sintaticamente a diferença entre esses dois moldes de conteúdo, como informam Sornicola (1995), Lambrecht (2000) e Sasse (2006), entre outros. A análise contrastiva funciona como recurso metodológico capaz de

2 As orações existenciais e apresentativas fariam parte do grupo das téticas.

3 Neste trabalho, usaremos 'enunciado' quando estivermos tratando do conteúdo proposicional da sentença em uso e 'sentença' quando nos ativermos à forma das expressões linguísticas. 
elucidar aspectos da sintaxe desse tipo de construção no PB e facilita a visualização das construções téticas, já que partimos da hipótese, avançada por nós em trabalhos anteriores (Pinheiro-Correa 2015, 2018) de que no PB contemporâneo não há diferença na ordem de palavras entre sentenças categóricas e a maior parte dos tipos de sentenças téticas.

\section{Teticidade}

A partir de um exame da expressão da teticidade em um variado conjunto de línguas, Sasse (1987) defende a ideia da existência universal de dois tipos de asserção distintos, codificados na sintaxe: téticos e categóricos. Segundo o autor, as sentenças téticas dão forma a enunciados de 'reconhecimento', diferentemente dos enunciados de predicação (categóricos). Constituem, portanto, dois tipos diferentes de asserção (SASSE, 1987, p. 555). A diferença na natureza desses enunciados seria que (i) a predicação corresponde à existência de uma entidade à qual será atribuída uma propriedade (o juízo duplo, do ponto de vista filosófico de Brentano 1973[1874] e Marty 1897) e (ii) o reconhecimento, característica dos enunciados téticos, que ocorre quando não existe um elemento que sirva de base da predicação; não há tópico sobre o qual predicar algo no comentário. Como informa Sasse ao descrever as condições por meio dos quais se dá o enunciado tético,

Se o enunciado não tem uma base de predicação, o estado de coisas é simplesmente estabelecido (ou 'reconhecido', como diria Marty). Uma entidade que casualmente esteja envolvida em um estado de coisas afirmado dessa maneira não pode ser tomada como base da predicação, mas sim, é apresentada como parte integrante do evento, daí não ser necessário que seja expressa por um elemento referencial. A entidade que serve como base da predicação sempre será autônoma - independente do evento predicado e localizada FORA dele: o evento é apresentado como uma propriedade sua. Já uma entidade envolvida em um simples reconhecimento se encontra DENTRO do evento e não pode ser concebida como uma entidade independente (SASSE, 1987, p. 555). ${ }^{4}$

Assim, o autor descreve a natureza não predicativa dos enunciados téticos. Ainda sobre a diferença entre enunciados téticos e categóricos, Sasse (1987) chama a atenção para o fato de haver uma confusão, na literatura pertinente, entre a "predicatividade no nível gramatical" e a "predicatividade no nível semântico-pragmático", no que diz respeito à ordenação dos elementos na sentença. A "predicatividade no nível gramatical” corresponde, no nosso caso, à disposição sintática sujeito-verbo (SV). Assim, se determinada sentença tem aparência de uma construção predicativa (por exemplo, com a ordenação SV) isso não garante que essa predicatividade no nível gramatical (sintático) corresponda automaticamente a uma estrutura categórica no nível semântico-pragmático:

A predicatividade gramatical explícita nem sempre expressa uma predicatividade no nível semântico-pragmático. O grau de predicatividade gramatical encontrado em expressões caracterizáveis como téticas depende, em amplo grau, do tipo de língua e, em particular, do grau de gramaticalização da relação sujeito-predicado (SASSE, 1987, p. 519). ${ }^{5}$

\footnotetext{
4 Do original em inglês: If the utterance lacks a predication base the state of affairs is simply posited ('recognized', as Marty would say). An entity that may happen to be involved in the state of affairs so asserted may not be picked out as the predication base, but is presented as part of the event; hence it need not be expressed by a referential element. While an entity serving as a predication base is always autonomous, that is, independent of and OUTSIDE the predicated event - this must be so since the event is presented as its property - an entity involved in a simple recognition is INSIDE the event and may not be conceived of as an entity al all.

5 Do original em inglês: Overt grammatical predicativity does not always express 'semanto-pragmatic' predicativity. The degree of grammatical predicativity found in expressions characterizable as thetic depends to a large extent, on the language type, and in particular on the degree of grammaticalization of the subject-predicate relation.
} 
Aqui, ao diferenciar esses dois tipos de predicatividade, o autor procura desfazer ainda outro malentendido, que se deixa entrever na literatura pertinente, por meio do qual se relaciona diretamente a ordem de constituintes na sentença e o status categórico ou tético do enunciado correspondente.

De acordo com o autor, a sentença tética tem as seguintes características:

a) o status informativo (dado / novo) da entidade envolvida não determina que uma sentença seja tética ou não;

b) a posição em relação ao verbo em que aparece o referente (por exemplo, o sujeito) na sentença não determina que seja categórica ou tética e

c) a entidade presente em uma sentença tética não tem autonomia no discurso, estando situada dentro da descrição de um estado de coisas.

Outra característica também relatada por Sasse está relacionada à expectativa que se tem sobre determinado enunciado na situação comunicativa (SASSE, 1987, p. 522). Quanto mais o enunciado romper com a expectativa sobre o tipo de informação que é esperada pelo interlocutor, mais teticidade ele apresenta, sendo, portanto, para este autor, um valor gradiente e não, exatamente, um traço completamente discreto.

Para marcar gramaticalmente a diferença entre uma sentença tética e uma categórica, o autor argumenta em prol de uma redução do caráter (gramaticalmente) predicativo da sentença. Tal redução pode se dar de diferentes maneiras, segundo a tipologia na qual se insere a língua: mudança da ordem SV para VS para expressar as téticas (caso do espanhol e do italiano, entre várias outras línguas, como as balcânicas); mudança do acento nuclear sem alteração sintática (caso de línguas germânicas, como o inglês, o holandês e o alemão) ou clivagem (caso do francês e do galês).

Abaixo, alguns exemplos, extraídos do texto:

Ordem VS (italiano):

(3) Cambia il governatore alla Bundesbank.

Muda o administrador no Bundesbank

"Administrador do Bundesbank é trocado"

Prosódia diferenciadora (alemão):

(4) SCHULBUS verunglückt

Ônibus-escolar bate

"Ônibus escolar sofre acidente"

Construção clivada [sujeito + oração relativa] (francês) ${ }^{6}$ :

(5) J'ai ma femme qui est malade!

Eu-tenho minha mulher que está doente

"Minha mulher está doente"

Segundo o autor, estes recursos destituem uma sentença pretensamente categórica da "divisão estrita entre sujeito e predicado das sentenças categóricas correspondentes” (SASSE 1987, p. 519). Serviriam para sinalizar ao interlocutor que a sentença não pertence informativamente ao grupo das categóricas.

Nesse sentido, também Lambrecht (2000, p. 625) defende a ideia de uma detopicalização dos sujeitos quando estes fazem parte de sentenças téticas ou de foco sentencial (de acordo com a nomenclatura do autor). E enumera as seguintes estratégias detopicalizadoras, com vários pontos em comum com aquelas apresentadas por Sasse (1987): (a) proeminência prosódica; (b) posição linear

6 Para esta tipologia, o autor não oferece exemplo de manchetes. Apresentamos um exemplo, fornecido por ele, de língua oral. 
(do sujeito) específica em relação ao verbo; (c) coocorrência com partículas focais; (d) ausência de concordância gramatical (do sujeito) com o verbo; (e) marcação de caso não nominativo; (f) status de constituinte único para a sequência verbo-objeto; $(\mathrm{g})$ restrições sobre a anáfora nula. Tais estratégias estão relacionadas ao que chamou de "princípio de neutralização entre sujeito e objeto" (LAMBRECHT, 2000, p. 626), aplicável às sentenças téticas.

No que diz respeito à estrutura argumental das sentenças téticas, este é motivo de controvérsia. Entre os autores que se dedicaram ao assunto, Lambrecht (2000) e Sornicola (1995), por exemplo, associam diretamente a teticidade à monoargumentalidade, ou seja, apenas sentenças monoargumentais poderiam ser téticas, sendo todas as outras, categóricas. Smit (2010), ao analisar a teticidade em diversas línguas africanas, não faz essa associação e Sasse (2006) discute o tema, mas o deixa inconcluso, defendendo uma interpretação laxa para o conceito, se ele for aplicável. No nosso entender, Sasse hesita em associar de maneira estrita as noções de teticidade e monoargumentalidade, diante de seu amplo conjunto de dados. Claramente, o autor diz que a monoargumentalidade não deve ser confundida nem com intransitividade nem com monovalência (SASSE, 2006, p. 277). E afirma ainda:

Entre as línguas que alternam entre SV e VS pesquisadas no estudo sobre a ordem VS, a monoargumentalidade pode ser vista às vezes, como uma tendência estatística, mas não, como uma restrição gramatical. Algumas línguas não são muito sensíveis à monoargumentalidade; (...). ${ }^{7}$ (SASSE, 2006, p. 278)

Os dados secundários de certas línguas com que trabalhou permitiam uma associação direta com a monoargumentalidade, porém tal associação não foi possível com dados de outras línguas e por isso, deixou o tema inconcluso.

Neste estudo entendemos, que a monoargumentalidade não é conditio sine qua non para a teticidade, uma vez que considerar téticas somente as sentenças monoargumentais equivale a apor um critério semântico prévio à análise pragmática, que é o que de fato determina a estrutura informativa da asserção, o que enviesa os resultados, a nosso ver. Construções transitivas podem ter o status de téticas se forem enunciadas, por exemplo, sem contexto prévio, já que, neste caso, constituem asserções inteiramente remáticas.

A função anunciativa é considerada por Sasse como uma das mais proeminentes configurações discursivas nas quais o complexo tético é relevante. Ela se revela nos chamados "enunciados tirados do nada", como gêneros discursivos específicos, exclamações monoproposicionais na língua falada (como no exemplo 1) e, no registro escrito, a anúncios publicitários e manchetes de jornal. No entanto, devemos fazer uma ressalva, não advertida em Sasse: nem toda manchete de jornal é tética, pois as manchetes podem também veicular conteúdos na disposição tema-rema ou tópico-comentário, quando, por exemplo, o referente é notório ou quando já vem ocupando o noticiário nos dias anteriores.

O português é citado de passagem em apenas um de seus trabalhos (SASSE, 1996, p. 15), como uma língua que funciona como o espanhol no que se refere à expressão da teticidade, ou seja, alternando a ordem SV para VS, porém o autor não esclarece se se trata do PB ou do português europeu nem cita a fonte. Tal como informado, nesta análise, partimos da hipótese de que as manchetes de jornal téticas do PB seguem o padrão de outros tipos de construções téticas nesta língua e não apresentam diferença na disposição sintática SV-VS em relação às manchetes categóricas.

7 Do original em inglês: Among the SV/VS alternating languages investigated in the VS study, monoargumentality can sometimes be observed as a statistical tendency, but not as a grammatical constraint, Some of the languages are not very sensitive to monoargumentality; (...). 


\section{A teticidade no PB}

\subsection{Kato (1989)}

Em uma análise gerativista na qual diferencia a sintaxe das construções de sujeito daquela das construções de tópico, Kato (1989) discute as construções em PB equivalentes àquelas apresentadas por Kuno (1973), que se diferenciavam por meio das partículas -ka para tópico (em sentenças categóricas) e -wa para sujeito não tópico (de sentenças téticas) e propõe a diferença entre sujeitos tópicos e não tópicos por meio da ordem de palavras: "o pneu furou" (tópico) e "furou o pneu" (sujeito não tópico) (KATO, 1989, p. 124). O primeiro exemplo, em nossa leitura, poderia corresponder a uma sentença categórica, com um sujeito-tópico e o segundo, a uma sentença tética, que apresenta um estado de coisas como um todo, sem predicar exclusivamente sobre um referente.

\subsection{Rodrigues e Menuzzi (2009)}

Os autores afirmam que o conteúdo correspondente ao comentário em determinada sentença "possui estrutura informacional interna". Eles se apoiam na proposta semântica de Vallduví (1992) para estabelecer a diferença entre a operação semântica desencadeada pelo FOCo presente em comentários de orações categóricas e aquela desencadeada pelas sentenças téticas. Usando as metáforas empregadas por Vallduví (1992), eles associam a interpretação do comentário de uma sentença categórica - o desempacotamento da informação - da seguinte maneira: a menção ao tópico ativa uma ficha, um registro, no qual alguma informação preexistente virá a ser modificada (através da expressão do comentário). O comentário estaria dividido em FOCO e TAIL. O TAIL indica qual é a proposição daquela ficha que vai ser modificada e o FOCO contém a modificação em si, sempre na ficha preexistente que corresponde ao tópico. Neste caso, o FOCO tem a propriedade de introduzir informação nova ou de corrigir uma pressuposição anteriormente inscrita na "ficha", funções propostas, por exemplo, na definição de Dik (1997) para o FOCo. Para o caso das sentenças téticas, não há uma "ficha" precedente a ser selecionada, porque não há tópico. Como comentam os autores, nesse caso:

No entanto, nem sempre há algum "registro" a ser modificado num dado arquivo: podese simplesmente registrar informação nova diretamente no arquivo, ou seja, fazer o que Vallduví \& Engdahl (1996) denominam default updating - que corresponde ao caso em que o comentário é todo focal. Nesse caso, a EI [Estrutura Informativa] da frase que desencadeia a atualização não conta com um tail - e, portanto, não instrui o ouvinte a buscar, no arquivo correspondente ao link, alguma proposição a ser atualizada. Isso pode ser ilustrado pelo exemplo abaixo (adaptado de Vallduví \& Engdahl 1996, ex. (17)):

(20) O presidente não gosta de receber presentes na Páscoa.

[Ele odeia CHOCOLATE]F.

A primeira sentença em (20) é responsável por "abrir" o arquivo correspondente ao SN $o$ presidente, anunciando que esse não gosta de presentes na Páscoa. O que vem em seguida é armazenado inteiramente no arquivo que se encontra aberto; e o pronome ele, na segunda sentença, não conta como um "link", pois sua função aqui é apenas a de "manter aberto" o arquivo, e não de abrir outro. Observe que, nesse caso, a noção de "tópico" sobre a qual falamos anteriormente não é equivalente a de "link" - na seção 3, pronomes como os da segunda sentença de (20) foram analisados como instâncias de um "tópico contínuo", presentemente ativo. De fato, como Vallduví observa, os chamados 'links' justamente sinalizam a abertura ou "ativação" de um novo tópico. (RODRIGUES; MENUZZI, 2009) 
Nessa passagem do texto, além de discutir questões interpretativas sobre os componentes dos dois tipos de asserção, os autores esclarecem que não é toda estrutura sujeito-predicado que corresponde necessariamente a um juízo categórico, como ilustra a segunda sentença de (20) discutida por eles. Esta observação corrobora a de Sasse (1987), no que se refere à "predicatividade no nível gramatical”.

\subsection{Pezatti (2012)}

Outra autora que se dedicou à relação entre ordem de palavras e tipos de asserção (que ela chama de "moldes de conteúdo", dentro da tradição da Gramática Discursivo-Funcional [GDF]) é Pezatti (2012, 2014), que em recente trabalho, (2012) estabelece algumas premissas para o português: com relação às sentenças categóricas, afirma que o português é uma língua 'categorial tópico-orientada' Isso significa que, entre as possibilidades tipológicas das línguas naturais, as categóricas (que podem ser orientadas para o tópico ou para o foco) no caso do português, são orientadas para o tópico, algo já notado por outros autores, como Pontes (1987) e Galves (1998). Observe-se que a autora estende seus achados para todas as variedades de português de forma geral e o corpus utilizado compreende oito variedades nacionais diferentes. No entender de Pezatti (2012), a sentença categórica contribui para "o avanço do discurso", correspondendo à FIGURA, nos termos da dicotomia FIGURA x FUNDO, de Hopper e Thompson (1980). E o faz aportando um referente - o tópico - no qual ancorar a informação nova constante do comentário.

No que se refere às sentenças téticas, estas “contribuem para a descrição ou montagem do cenário no avanço do Discurso": este tipo de asserção está associado à noção de FUNDO de Hopper e Thompson (1980), propiciando ao falante a possibilidade de "sustentar, ampliar ou comentar a linha principal do discurso" (PEZATTI, 2012, p. 381).

Assim, a ordem não marcada das sentenças téticas em português, segundo a autora, é VS. Uma vez definido no denominado nível interpessoal (de acordo com a GDF) que a oração inteira, por ser focal, tem um molde de conteúdo que não admite um tópico, toda a oração vai estar relacionada ao domínio de PF, a posição final da oração (PEZATTI 2014, p. 93-94). Esta posição, considerada psicologicamente saliente, tipicamente abriga focos.

Uma análise dos exemplos apresentados por Pezatti (2012, 2014), no entanto, mostra que a escolha das sentenças que esta autora considera téticas é fortemente influenciada pela semântica do verbo e tais dados não correspondem à definição de sentença tética presente em Kuroda (1972), Sasse (1987) ou em Rodrigues e Menuzzi (2009). Em Pezatti (2012) se afirma:

Construções téticas, no Nível Representacional, correspondem a moldes de predicação de propriedade de zero lugar, conforme exemplifica (18); de um lugar, como se vê em (19), que tem sido denominada construção VS, porque o sujeito, não sendo o Tópico, posicionase depois do verbo.

(18) começou a relampejar

(19) já aconteceram vinte e um, vinte e uma erupção

Nessas construções a palavra verbal e seu argumento, quando houver, constituem uma unidade fechada que, ao descrever uma situação, não especifica qualquer elemento como ponto de partida e ponto de vista.

(PEZATTI, 2012, p. 371-372)

A autora assume que as construções téticas correspondem a verbos de zero e de um argumento, não havendo lugar na sua definição para os verbos de dois argumentos. Para muitos outros autores, no entanto, entre eles, Smit (2010), Hannay e Martínez Caro (2008), o que define ou não se uma sentença 
é tética não é a quantidade de argumentos que um verbo tem, e sim, o papel (não) topical dos referentes ali presentes. O próprio exemplo (20) de Vallduví (1992) discutido por Rodrigues e Menuzzi (2009) é de um predicado de dois lugares. Observando a definição de Pezatti $(2012,2014)$ chega-se à conclusão de que as sentenças téticas por ela descritas estão diretamente associadas às construções com verbos meteorológicos, às construções apresentativas e às denominadas inacusativas, caracterizadas por serem monoargumentais com sujeitos não agentivos. Fica subentendido que todos os verbos de dois ou mais lugares, nas definições da autora, correspondem necessariamente a sentenças categóricas. Essa definição é contrária àquelas presentes em Sasse (1987) e Lambrecht (2000).

\subsection{Pinheiro-Correa (2015)}

$\mathrm{O}$ autor defende que, à diferença do espanhol, no $\mathrm{PB}$ as sentenças téticas tendem a ser construídas na ordem SV. Em um estudo em que compara os diálogos originais de dois filmes argentinos com a dublagem ao português brasileiro, o autor, através do estudo de um corpus paralelo, mostra que sentenças téticas do espanhol, caracterizadas pela ordem VS eram dubladas na ordem SV em PB exceto quando as construções eram inacusativas. Outra característica da dublagem em PB foi que sujeitos não topicais, marcados nos diálogos originais em espanhol no caso dativo foram convertidos em sujeitos nominativos em PB, na ordem SV, mesmo em contextos não agentivos, o que vem a ser, nos dados do espanhol, uma instância do item (e) das estratégias detopicalizadoras propostas por Lambrecht (2000), denominado "marcação de caso não nominativo", que também não foi observada na dublagem ao PB.

\section{Corpus e Metodologia}

A metodologia de obtenção dos dados foi a seguinte. Procedeu-se à recolha e organização de manchetes e as respectivas notícias (não analisadas neste estudo) de quatro jornais on-line, dois brasileiros, da cidade do Rio de Janeiro (O Globo e Jornal do Brasil) e dois argentinos, da cidade de Buenos Aires (Clarín e La Nación). A escolha destes jornais se deveu aos seguintes fatores: (a) são jornais tradicionais e dirigidos à classe média e (b), pela última razão, apresentam uma editoria de notícias internacionais extensa, de onde obtivemos os dados para a pesquisa. Escolhemos também, jornais estrangeiros provenientes de uma mesma localidade, como amostra, neste caso do espanhol da macrovariedade do cone sul, especificamente, da cidade de Buenos Aires, denominado aqui, espanhol argentino (EA).

O critério de seleção dos dados foi o seguinte: para que fosse possível aproveitar uma notícia como dado, esta tinha que aparecer veiculada em pelo menos um jornal de cada país. O período de recolha dos dados foi entre os meses de abril e outubro de 2010. No total foram recolhidas 48 notícias da editoria Internacional que satisfaziam os critérios, divididas casualmente em 24 manchetes brasileiras e 24 argentinas, em 17 conjuntos de notícias, cada um sobre exatamente o mesmo assunto. Obtivemos, assim, grupos de duas notícias (quando aparecia uma em um jornal de cada país), de três e de quatro (quando a mesma notícia aparecia nos dois jornais de cada país). Foram 6 grupos de duas notícias, 8 de três notícias e 3 de quatro notícias. Como informado, a análise para o presente estudo se concentrou apenas nas manchetes.

Para melhor visualização dos constituintes, a transcrição sintática efetuada baseou-se no modelo de Blanche-Benveniste et al. (1979), que permite observar claramente a presença ou ausência dos constituintes no eixo paradigmático. A figura 1 abaixo traz o exemplo de um grupo. 
Figura 1 - Exemplo de grupo de manchetes no diagrama de Blanche-Benveniste et al. (1979)

\begin{tabular}{|l|l|l|l|l|l|l|}
\hline País & Locativo & Sujeito & $\begin{array}{l}\text { Verbo voz } \\
\text { ativa }\end{array}$ & $\begin{array}{l}\text { verbo } \\
\text { voz } \\
\text { passiva }\end{array}$ & Adjunto & Argumento \\
\hline Brasil/JB & & & & & & \\
\hline O Globo & & Aeroportos & reabrem & & $\begin{array}{l}\text { em parte da } \\
\text { Europa, com } \\
\text { muitos voos } \\
\text { cancelados }\end{array}$ & \\
\hline $\begin{array}{l}\text { Argentina/ } \\
\text { Clarin }\end{array}$ & & & Levantan & & & $\begin{array}{l}\text { restriciones a } \\
\text { los vuelos em } \\
\text { Europa }\end{array}$ \\
\hline La Nación & & & Reabren & & & $\begin{array}{l}\text { casi todos los } \\
\text { aeropuertos de } \\
\text { Europa }\end{array}$ \\
\hline
\end{tabular}

Fonte: dados da pesquisa. Elaborado pelo autor

O exemplo é de um grupo de três manchetes. A linha vazia indica que o Jornal do Brasil não deu a notícia. As casas de sujeito vazias nas manchetes argentinas permitem comparar a disposição sintagmática das manchetes.

\section{Resultados e discussão}

Dentre os 24 dados argentinos, 3 deles foram de sentenças categóricas, 19 de téticas e 2 que por ora deixamos sem classificar ${ }^{8}$. Dentre os dados brasileiros, 19 deles foram de téticas e 5 deles, de categóricas.

\subsection{Categóricas}

As manchetes categóricas em ambas as línguas se caracterizaram pela disposição SV dos seus constituintes. As três manchetes do EA de estrutura informativa categórica foram as seguintes:

É o caso das manchetes seguintes (o tema foi colocado em negrito):

(6a) El rey Juan Carlos fue operado del pulmón con éxito

(7a) La OMS declaró el fin de la pandemia de la gripe A

(8a) El eclipse total sólo se pudo disfrutar en El Calafate

Os exemplos (6) e (7) apresentam referentes que são de notório conhecimento (o rei espanhol Juan Carlos e a Organização Mundial da Saúde [OMS]), sendo de status informativo dado (Prince 1981), devido ao fato de um deles ser uma personalidade do mundo hispânico, frequente nos noticiários (exemplo 6) e o outro, porque era um órgão mencionado diariamente pela mídia durante a epidemia da gripe suína, de quando data a notícia (exemplo 7a). Isso permitiu que aparecessem sujeitos explícitos nestas manchetes do espanhol, devido ao fato de serem sujeitos-tópicos. O exemplo (8a) confirma a análise anterior, de manchete de estrutura informativa categórica, uma vez que a notícia do jornal Clarín, do dia 11/07/2010, trata do eclipse solar como um elemento dado, através de um SN determinado e aparece um dia depois da seguinte notícia, veiculada pelo mesmo jornal, em que o eclipse é noticiado como elemento novo, por meio de um sintagma indeterminado e em posição final,

8 As outras duas manchetes do espanhol são as seguintes: Un detenido por el fallido atentado a Times Square ("um detido pelo atentado frustrado na Times Square"), que consideramos não analisável por deixar de apresentar verbo e Cientos de personas disfrutaron del eclipse total del sol ("centenas de pessoas desfrutaram do eclipse total do sol"), que por ora deixaremos sem analisar. 
isto é, fora da posição de tópico, em uma sentença tética: Desde el sur de la cordillera se verá mañana un eclipse total ("No sul da cordilheira, amanhã será visto um eclipse total").

As contrapartes brasileiras não preservaram exatamente o caráter categórico de todas as manchetes, no que se assenta a dificuldade de identificar sentenças téticas no PB. Os dados brasileiros das contrapartes dos exemplos argentinos se caracterizaram pela ordem SV:

(6b) O Globo: Rei espanhol Juan Carlos tem nódulo benigno retirado do pulmão

(7b) JB: OMS considera encerrada epidemia de gripe suína

(7c) O Globo: OMS diz que ciclo da pandemia H1N1 chegou ao fim

(8b) O Globo: Eclipse total do sol, só visto da Ilha de Páscoa, é acompanhado por milhares

No caso de (8b) ainda que o referente apareça sem determinante, ele já vinha sendo tratado no noticiário do jornal em questão nos dias precedentes, sendo, portanto, temático, como informa a manchete de O Globo de 09/07/2010: "Eclipse solar será visto apenas em parte do hemisfério sul". Dessa maneira, é possível afirmar que se trata de uma sentença que foi considerada como categórica. Como veremos na seção seguinte, o conhecimento contextual / cotextual é um dos poucos recursos que permitem diferenciar no PB uma sentença categórica de uma tética.

\subsection{Téticas}

Diferentemente do previsto por Sasse (2006), a ordem de palavras predominante nas manchetes dos jornais brasileiros não foi VS. De qualquer modo, houve uma marcada diferença na disposição de manchetes téticas e categóricas. Outros estudos corroboram a ordem VS para outros tipos de téticas no espanhol (Lambrecht 2000. Pinheiro-Correa 2015; 2018a), inclusive anunciativas, que não envolviam manchetes de jornal. As manchetes téticas do espanhol se caracterizaram sistematicamente pelo verbo em primeira posição, conjugado na terceira pessoa do plural e ausência de SN de sujeito, em uma configuração de sujeito indeterminado. De 24 manchetes, essa configuração apareceu em 19 delas (80\%). Os dados do espanhol mostram que a totalidade das manchetes téticas correspondeu à configuração de sujeito indeterminado. Dos 24 dados do PB, 19 deles foram de manchetes téticas e a totalidade deles exibiram a ordem SV. Abaixo, um exemplo de um típico conjunto de manchetes téticas.

A típica construção tética do PB é exemplificada pelo grupo 11, que trata da prisão de um líder do grupo terrorista basco ETA. Este assunto foi noticiado nos quatro jornais.

(9a) JB: Chefe do ETA é preso em operação policial

(9b) O Globo: Polícia da França prende líder militar do ETA

(9c) La Nación: Detienen en Francia al jefe del aparato militar de ETA

(9d) Clarín: Detienen en Francia al máximo dirigente de ETA

Nos exemplos em (9) os dois jornais argentinos (exemplos [9c] e [9d]) noticiam a prisão iniciando a sentença pelo verbo, sem expressão do SN de sujeito, em uma construção de sujeito indeterminado, com o verbo na terceira pessoa do plural. Nos exemplos brasileiros, observa-se a construção recorrente em todas as 24 manchetes do corpus: a disposição sujeito-verbo (SV), independentemente de se a manchete é categórica ou tética, como mostramos acima.

A disposição sujeito-verbo dos dados do PB mostram que, neste gênero especifico, pelo menos, o PB se comporta de maneira inversa a outras línguas românicas, como o espanhol e o italiano, citadas por Sasse (2006) em seu estudo comparativo, pelo fato de não apresentar diferença entre manchetes categóricas e téticas por nenhum dos recursos descritos por Sasse (2006) nem por Lambrecht (2000). Algumas observações podem ser feitas a partir deste conjunto de exemplos: o sujeito da manchete (9b) do PB não é imprescindível, em termos informativos, uma vez que "prender" é uma atribuição das polícias e a mesma manchete em espanhol carece do sujeito explícito e, mesmo assim, não há diferença na sua compreensão. Nos dois casos, um estado de coisas é apresentado. No entanto, a 
apresentação do estado de coisas sem associar a ideia de predicação a nenhum referente citado se dá de maneira inversa entre as duas línguas. No espanhol, o referente sobre o qual poderia ser estabelecida a predicação nem é citado. Este poderia ser o recurso detopicalizador nas manchetes naquela língua. No PB, a apresentação do mesmo estado de coisas envolveu a obrigatória apresentação do sujeito nos dois casos. Em (9a) em uma passiva sintática, em que o sujeito é "chefe do ETA" e em (9b) em uma ativa em que o sujeito é "polícia da França". Os sujeitos mudam, mas o estado de coisas veiculado permanece o mesmo, com alguma diferença na perspectiva comunicativa. O que os dois exemplos têm em comum é a presença de um SN explícito de sujeito na posição pré-verbal, abrindo a sentença. Quando ele é tópico, como no caso das categóricas, é o esperado em uma estruturação tema-rema, de acordo com o princípio da progressão temática: a informação temática, de menor carga informativa serve de suporte para ancorar a informação remática, que tende a ocupar a porção final da sentença (cf. DANEŠ 1974). Porém ele aparece também nas sentenças téticas, como em outro grupo de exemplos, abaixo:

(10a) La Nación: Logran recrear los instantes posteriores al Big Bang

(10b) JB: Cientistas anunciam colisão de partículas similar ao Big Bang

Novamente, a manchete do PB apresenta o sujeito explícito, na configuração SV, diferentemente da manchete argentina, com construção de sujeito indeterminado, iniciada pelo verbo e sem expressão ao SN de sujeito. O sujeito da manchete brasileira é "Cientistas" e o da manchete argentina é indeterminado.

Considerando que também aqui, o agente não marcado da descoberta de fatos científicos são os sujeitos dedicados à pesquisa, a identificação de "cientistas" como sujeito da "descoberta" é uma informação semanticamente prescindível, o que fica evidente, uma vez mais, na comparação com o espanhol.

A questão da existência de sujeito em todas as manchetes do PB parece ser de ordem sintática, e não, informativa. Sasse (1987) recorda que não é a disposição SV ou VS que determina a estrutura informativa de uma oração, porque a distribuição dos sujeitos das orações téticas depende do grau de gramaticalização da relação sujeito-predicado em cada língua. Se, em espanhol, a ausência de SN de sujeito e o início da sentença pelo verbo é indício de uma estrutura informativa unimembre, tética, no PB contemporâneo pode ser que ambas as estruturas informativas: categórica ou tética tendam à ordem $\mathrm{SV}$, devido a questões de gramaticalização da ordem de constituintes.

A disposição SV das manchetes téticas e também das categóricas do PB dá a estas construções uma ideia de indeterminação quanto à teticidade, como se o status informacional do referente (Prince 1981) não fosse uma informação a ser levada em conta na operação cognitiva que determina a forma da construção tética. Os dados abaixo mostram uma diferenciação sintática quanto ao status tético ou categórico da sentença no espanhol e uma ambiguidade na manchete equivalente no PB:

(11a) LaNación: Brasil: asesinan a un comisario mientras lo entrevistaba una radio

(11b) O Globo: Delegado é morto em entrevista ao vivo na Bahia

(11c) JB: BA: delegado de Camaçari é assassinado durante entrevista

O exemplo (11a), do espanhol, informa que se trata de um delegado não especificado, ideia também presente na manchete de O Globo (11b), por meio do nominal simples "Delegado". A manchete do JB (11c) traz "Delegado de Camaçari". Este SN pode receber tanto interpretação não específica, (considerando-se que Camaçari-BA tenha mais de uma delegacia), como específica (considerandose que a cidade tenha apenas uma delegacia). Esta última hipótese poderia levar a uma interpretação categórica da manchete do JB, em que "Delegado de Camaçari", elemento plenamente identificado, ainda que carente de determinante, seria tópico e o restante da notícia, o comentário, em uma estrutura informativa bipartida. Por outro lado, a indeterminação de "delegado" na manchete de O Globo (11b) não permite uma leitura categórica, apenas tética, o que demonstra mais uma vez que tanto manchetes categóricas quanto téticas no PB contemporâneo apresentam a ordem SV. 


\section{Conclusão}

O estudo contrastivo de manchetes de jornais brasileiros e argentinos permitiu visualizar características sintáticas de construções téticas do PB no gênero manchete de jornal, classificado por Sasse (2006) como téticas do tipo apresentativo. Os resultados demonstraram que, enquanto as manchetes de estrutura informativa categórica do PB apresentavam a ordem SV, e neste ponto se comportavam de maneira semelhante aos dados do espanhol, as manchetes téticas (19 dados de um total de 24) apresentaram a mesma ordem sujeito-verbo (SV) das categóricas, sem exceção. Neste ponto, se diferenciaram radicalmente dos dados do EA, cujas manchetes téticas corresponderam, sem exceção, a sentenças de sujeito indeterminado, sem expressão do SN de sujeito e iniciadas pelo verbo. Assim, os dados do PB revelaram que não houve diferença na ordem de constituintes entre sentenças categóricas e téticas, no que se refere às téticas anunciativas encontradas em manchetes de jornal, de maneira que, diferentemente das outras línguas românicas, a teticidade não pareceu ser marcada nos dados de PB contemporâneo.

\section{Apêndice}

Grupos de manchetes

Assunto 1: Aeroportos reabrem na Europa.

O Globo: Aeroportos reabrem em parte da Europa com muitos voos cancelados

La Nación: Reabren casi todos los aeroportos de Europa, pero se vigila intensamente la nube de cenizas

Clarín: Levantan restricciones a los vuelos en Europa

Assunto 2: Pichação na estátua do Cristo Redentor

O Globo: Cristo Redentor foi pichado com assinaturas e inscrições de protesto

La Nación: Brasil: pintan con aerosol el Cristo Redentor

Assunto 3: Descoberta de possível ancestral do homem na África do Sul.

O Globo: Cientistas identificam possível novo ancestral do homem na África do Sul

La Nación: Descubren una especie de homínido desconocido en Sudáfrica

Assunto 4: Transplante de rosto.

JB: Hospital mostra como foi realizado transplante total de rosto

O Globo: Hospital na Espanha afirma ter feito o primeiro transplante facial total

La Nación: Realizan por primera vez un trasplante total de cara

Assunto 5: Avião da Air France.

JB: França localiza caixas-pretas do voo AF 447

La Nación: Localizan las cajas negras del avión de Air France que cayó al atlántico

Assunto 6: Operação do rei Juan Carlos.

O Globo: Rei espanhol Juan Carlos tem nódulo benigno retirado do pulmão

La Nación: El Rey Juan Carlos de España fue operado del pulmón con éxito

Clarín: Operaron con éxito al rey Juan Carlos de España de un nódulo pulmonar 
Assunto 7: Fazendeiro fere crianças em escola na China.

JB: Novo ataque em creche da China deixa cinco crianças feridas

O Globo: Fazendeiro fere cinco crianças em novo ataque a escola na China

La Nación: China: hieren a 28 niños en un jardín

Assunto 8: Paquistanês que atacou Bombaim é condenado à morte.

O Globo: Paquistanês que atacou Bombaim em 2008 é condenado à morte

Clarín: Condenan a muerte al único detenido por los atentados en Bombay de 2008

Assunto 9: Preso suspeito de tentativa de atentado em Nova York

JB: Times Square: suspeito diz que agiu sozinho e nega ligação com Al Qaeda

O Globo: Suspeito de tentativa de atentado em Nova York é preso

La Nación: Un detenido por el fallido atentado en Times Square

Clarín: Coche bomba en Nueva York: detienen a un sospechoso al querer salir del país

Assunto 10: Terroristas do ETA são condenados a mais de mil anos de prisão

JB: Terroristas do ETA pegam mais de mil anos de prisão

La Nación: Condenan a más de mil años de cárcel a tres etarras

Clarín: España: condenan a tres etarras a más de mil años de cárcel

Assunto 11: Prisão do chefe do ETA

JB: Chefe do ETA é preso em operação policial

O Globo: Polícia da França prende líder militar do ETA

La Nación: Detienen en Francia al jefe del aparato militar de ETA

Clarín: Detienen en Francia al máximo dirigente de ETA

Assunto 12: Assassinato do delegado de Camaçari

JB: BA: delegado de Camaçari é assassinado durante entrevista

O Globo: Delegado é morto em entrevista ao vivo na Bahia

La Nación: Brasil: asesinan a un comisario mientras lo entrevistaba una radio

Assunto 13: Eclipse total.

JB: Eclipse total anima estudiosos

Clarín: Desde el sur de la cordillera se verá mañana un eclipse total

Assunto 14: Acompanhamento do eclipse total

O Globo: Eclipse total do sol, só visto da Ilha de Páscoa, é acompanhado por milhares

La Nación: Cientos de personas disfrutaron del eclipse total de sol

Clarín: El eclipse total sólo se pudo disfrutar en El Calafate

Assunto 15: Fim da pandemia de gripe suína

JB: OMS considera encerrada epidemia de gripe suína

O Globo: OMS diz que ciclo da pandemia H1N1 chegou ao fim

La Nación: La OMS declaró el fin de la pandemia de la Gripe A

Clarín: Declaran el fin de la pandemia por la Gripe A 
Assunto 16: Luta contra a malária

O Globo: Mosquito geneticamente modificado pode ajudar na luta contra a malária La Nación: Crean mosquitos inmunes a la malaria

Assunto 17: Liberação de preso político em Cuba.

JB: Preso político paraplégico é libertado em Cuba

O Globo: Dissidente cubano é autorizado pelo governo a viajar para os EUA um mês após sua libertação

La Nación: Cuba: excarcelaron a un disidente. 


\section{Referências}

BLANCHE-BENVENISTE, Claire. Études de textes de français parlé: syntaxe et variation. BLANCHE-BENVENISTE, Claire et al. Théories et pratiques de la sociolinguistique, Rouen, 1979. 305-314.

BRENTANO, Franz. Psychology from an empirical point of view. London: Routledge and Kegan Paul, 1973 (1874).

DANEŠ, František. Functional sentence perspective and the organization of the text, in Daneš (ed.). Papers on Functional Sentence Perspective. Prague: Academia, the Hague: Mouton, 1974.

DIK, Simon C. The Theory of Functional Grammar. Complex and Derived Constructions. Berlin and New York: Mouton de Gruyter, 1997.

HANNAY, Mike; MARTÍNEZ CARO, Elena. 2008. Last things first: An FDG approach to clausefinal focus constituents in Spanish and English. In: GÓMEZ GONZÁLEZ, M. A. et al. Languages and Cultures in Contrast and Comparison. Amsterdam \& Philadelphia: John Benjamins, 2008.

HOPPER, Paul and THOMPSON, Sandra A. Transitivity in Grammar and Discourse. Language, 56, 251-299, 1980.

KATO, Mary A. Tópico e sujeito: duas categorias na sintaxe? Cadernos de Estudos Linguísticos, Campinas, 17. 109-131, 1989.

KUNO, Susumu. Functional sentence perspective. A case study from Japanese and English. Linguistic Inquiry, 3, 1972.

KUNO, Susumu. The structure of the Japanese language. Cambridge, Mass.: The MIT Press, 1973. KURODA, Sige-Yuki. The categorical and the thetic judgment. Foundations of Language, 2, 1972. LAMBRECHT, Knud. When subjects behave like objects: An analysis of the merging of $\mathrm{S}$ and $\mathrm{O}$ in sentence-focus constructions. Studies in Language, 24.3, 2000.

PEZATTI, Erotilde Goreti. Ordenação de constituintes em construções categorial, tética e apresentativa. D.E.L.T.A., São Paulo, 28:2, 2012.

PEZATTI, Erotilde Goreti. A ordem de palavras no português. São Paulo, Parábola, 2014.

PINHEIRO-CORREA, Paulo. Características das construções de foco sentencial no português, em um estudo de corpus paralelo. ReVEL, Ed. especial n.10, 195-22, 2015.

PINHEIRO-CORREA, Paulo. La sintaxis de los enunciados téticos y categóricos en dos traducciones de Corazones Solitarios de Rubem Fonseca al español. Trabalhos em Linguística Aplicada v.57, n.1, 229-43, 2018a.

PONTES, Eunice. O tópico no português do Brasil. Campinas: Pontes, 1987.

PRINCE, Ellen F. Toward a taxonomy of given/new information. In: COLE, Peter. Radical Pragmatics. New York: Academic Press, 1981.

RODRIGUES, Gabriel Roisemberg; MENUZZI, Sérgio de Moura. Estrutura Informacional. Manuscrito. Michighan State University, 2009.

SASSE, Hans-Jürgen. The thetic / categorical distinction revisited. Linguistics 25, 1987.

SASSE, Hans-Jürgen. Theticity. Arbeitspapier 27 (Neue Folge), Universität zu Köln, Institut für Sprachwissenschaft, 1996.

SASSE, Hans-Jürgen. Theticity. In G. Bernini and M. L. Schwarz. Pragmatic organization of discourse in the languages of Europe. Berlin: Mouton de Gruyter, 2006.

SMIT, Niels. Theory and Typology of information packaging. Amsterdam: University of Amsterdam, 2010. 
SORNICOLA, Rosanna. Theticity, VS order and the interplay of syntax, semantics andpragmatics. Sprachtypologie und Universalienforschung, 48, 1995.

VALLDUVÍ, Enric. The Informational Component. New York: Garland, 1992. 